\section{Dynamic and Traditional Greenhouse Climate Regimes: Influx of Thrips (Thysanoptera)}

\author{
Lene Jakobsen ${ }^{1}$ \\ KVL, Department of Agricultural Science, DK-2630 Taastrup
}

Michael Brogaard, Annie Enkegaard, and Henrik F. Brødsgaard
Danish Institute of Agricultural Sciences, Department of Integrated Pest
Management, DK-4200 Slagelse, Denmark

Jesper M. Aaslyng

KVL, Department of Agricultural Science, DK-2630 Taastrup

Additional index words. vents, thrips, pests

\begin{abstract}
Dynamic climate regimes have been developed mainly to reduce energy consumption in the greenhouse, and this has been the main reason for their adoption by growers. During recent years, Danish growers have observed that problems with pests have diminished since they changed from the traditional rigid climate regime to a dynamic regime. The trend has also been observed in scientific experiments testing different dynamic climate regimes. The present experiment shows that the influx of thrips from outside into the greenhouse was reduced by $\mathbf{4 0 \%}$ under a dynamic climate regime compared to a traditional rigid regime, and that this was related to the opening degree of the vents. Vents were open on average $7 \%$ under the dynamic regime and $33 \%$ in the traditional climate. The influx of thrips was linearly correlated with density outside the greenhouse $(P<0.0001)$ and with opening degree of the vents $(P=0.0001)$.
\end{abstract}

IntelliGrow is a Danish dynamic climate control concept in which climate control is by the physiological responses of plants, the outside irradiance and microclimate of the plants within the greenhouse. $\mathrm{CO}_{2}$ and heat are supplied only when the plants can make optimal use of it, i.e., when light intensity is sufficient for a high photosynthesis rate (Aaslyng et al., 1999). In a dynamic climate the temperature fluctuates in a broader span than in a traditional climate. Under a dynamic climate regime, growers use lower night and day setpoints for temperature, combined with a higher ventilation setpoint temperature, than they would in the traditional climate regime. On sunny days the average temperature will be higher in a dynamic climate than in a traditional climate due to the higher irradiance and therefore also a higher temperature set point, but also due to a higher ventilation setpoint. On the contrary, on cloudy days with little light outside the average temperature will be lower in a dynamic climate than in a traditional climate, due to a lower temperature set point. In the dynamic climate natural heating from the sun is used as much as possible and therefore the overall heat consumption is lower in a dynamic compared to a traditional climate

\footnotetext{
Received for publication 7 July 2005. Accepted for publication 2 Jan. 2006. This work was funded by the Directory for Food, Fishery and Agri Business. We are grateful to Jens Berthelsen for management of the plants and greenhouse technique, HanneBirgitte Christiansen for laboratory assistance and Jakob Markvart, Anders Gammelvind and Jakob Skov Petersen for assistance when handling plants. ${ }^{1}$ Corresponding author; e-mail lenj@kvl.dk.
}

The major objective of research in the field of dynamic climate regimes has been to reduce energy consumption, but in Denmark growers have observed that, by changing from the traditional rigid climate regime to a dynamic climate regime, pest problems have decreased and consequently the need for treatment. Growers claim that their use of pesticides was reduced after they changed to a dynamic climate regime. Also in scientific experiments, where the effect of different dynamic climate regimes on energy consumption and plant growth has been investigated (Jakobsen et al., 2003), a tendency towards fewer pests has been observed by the assisting gardeners. One of the reasons for the observed effects of dynamic climate regimes on the influx of pests from outside the greenhouse could be the changed venting strategy.

In addition to harming the plants, pests colonizing greenhouses from outdoors may hamper the control of other pests already present in the greenhouse. An influx of pests therefore influences the choice and timing of pest control measures. Among various pests immigrating into the greenhouse under Northern European climate conditions are thrips, e.g., the grain thrips, Limothrips cerealium (Thysanoptera: Thripidae) (Larsen, 2000); aphids such as the cereal aphid Sitobion avenae (Fabricius) (Hom.: Aphididae); moths such as the silvery moth Autographa gamma (Linnaeus) (Noc.: Plusiinae) (Stubsgaard, Borregaard Bioplant, personal communication); and butterflies such as the cabbage white butterfly Pieris brassicae (Linnaeus) (Lep.: Pieridae) (Hansen, 2003). The risk of pest influx is highly seasonal (e.g., grain thrips is most abundant in late August, when cereals are harvested). However, there is very limited published data of the influx of pests into greenhouses in Northern Europe.

During recent years, researchers have been searching for methods by which to minimize the influx of pests from outside the greenhouse. One method that has been proposed is use of insect-proof nets in all vents in the greenhouse. Researchers investigating the usability of different types of nets have found that mesh size is important (Montero, 1999; Larsen, 2000; Hanafi et al., 2003). While a very fine mesh is needed to hinder certain pests, this tends to impede air exchange and thus air circulation and a rise in temperature and increase in humidity often result (Fatnassi et al., 2002; Molina-Aiz et al., 2004). According to the Danish Growers'Association(DEG), less than $5 \%$ of Danish growers use insect nets (Larsen, DEG, personal communication).

Reduced energy consumption is the main reason that many growers adopt use of the dynamic climate system. However, as growers have observed an effect of a dynamic climate on pests it is important to know how a dynamic climate influences the influx of pests from outside. In the future, it might be the actual effects on pests that are important in the decision-making involved in choosing climate regimes. An experiment was therefore conducted to examine how pest influx is influenced by the climate regime. Thrips were chosen as the model in the present experiment, as some thrips species are main pests to enter greenhouses in Denmark.

\section{Material and Methods}

In the period February to December 2004, the influx of thrips in eight greenhouse compartments $\left(25 \mathrm{~m}^{2}\right.$ each) was monitored. Four compartments faced south while four faced north in the same wide-span greenhouse situated at the KVL Research Farm in the countryside near Copenhagen $\left(55.41^{\prime} \mathrm{N} ; 12.33{ }^{\prime} \mathrm{E} ; 28 \mathrm{~m}\right.$ above MSL). The greenhouse is surrounded by lawns and cornfields. Two benches, 133 plants on each (Begonia elatior hybrid var. Blitz.), were sited in each compartment. Begonia was chosen as a model plant as earlier experiments had shown that Begonia can be grown easily in a dynamic climate regime similar to the one used in the present experiment (Jakobsen et al., 2003).

Adynamic climate regime was compared to the traditional climate regime used by Danish Begonia growers. Both climate regimes were implemented in two compartments on the north and two on the south side of the greenhouse. Sticky traps $(10 \times 20 \mathrm{~cm})$ were placed just inside the vents to monitor the influx of pests. Blue and yellow sticky traps were chosen as they are common used commercial available sticky traps. Eight traps (four yellow and four blue) were used in each compartment, constituting approximately one plate per meter of vent $(2$ vents, span $3 \mathrm{~m}$ each) (Fig. 1). To monitor the presence of thrips outside the greenhouse, two traps (one yellow and one blue) were placed at the top of each of four poles (each $4 \mathrm{~m}$ high, about the same height as the vents 


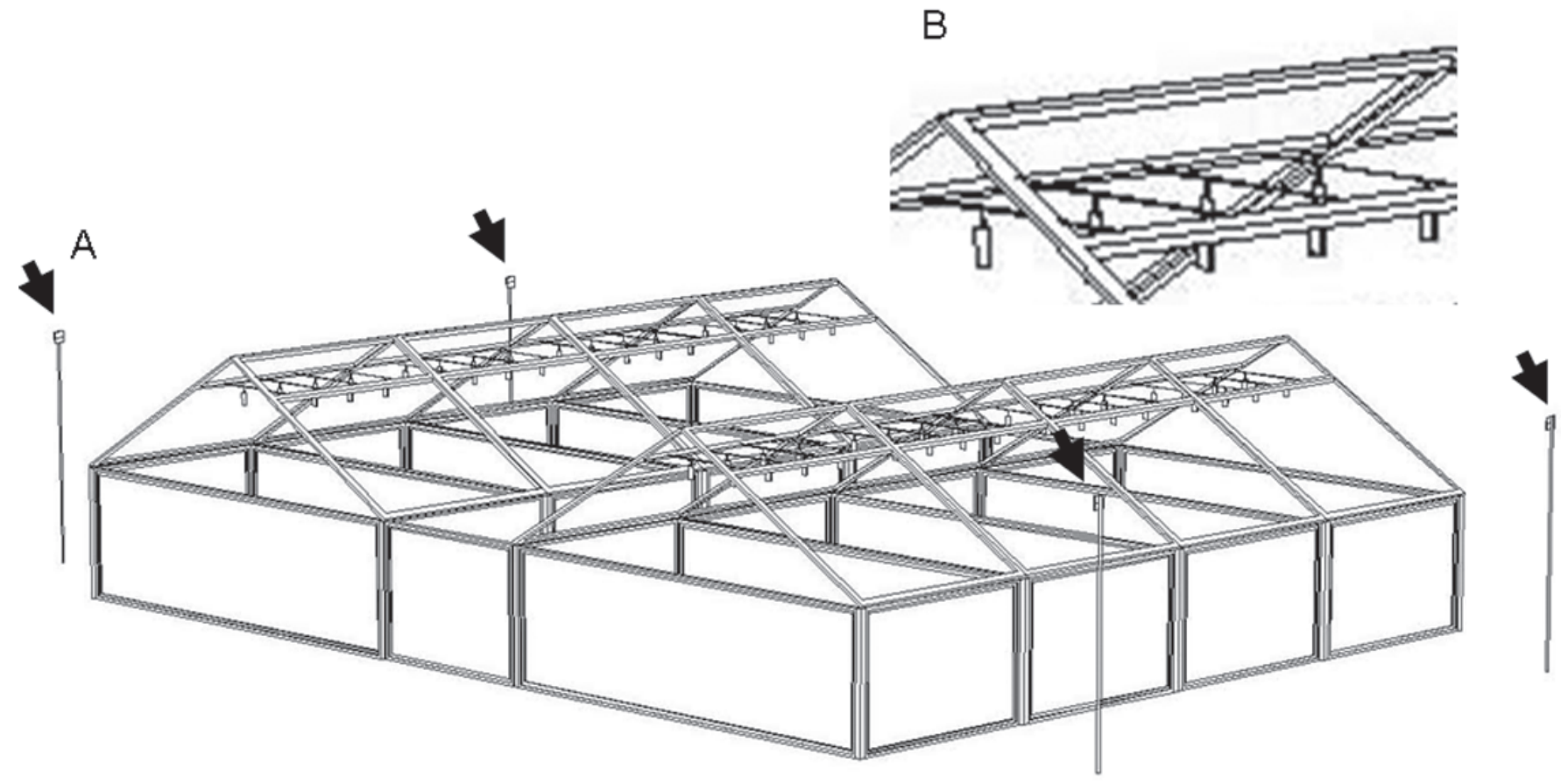

Fig. 1. Location of sticky traps within each greenhouse compartment and the location of all eight compartments (A). Arrows indicates the position of placement of sticky traps. (B) Blown up of one compartment.

in the greenhouse), two of them located along the south side, and two along the north side of the greenhouse, all at a distance of about $3 \mathrm{~m}$ from the greenhouse.

Each week, all traps were replaced and the number of thrips on each trap was counted. The traps were looked at under a microscope to ensure the identity of insects in the order of thrips, however, the thrips were not identified to species.

Climatestrategies. The two climate regimes were obtained using a LCC1200 commercial environmental climate computer (Senmatic, Denmark). The traditional climate regime had fixed setpoints for heating and ventilation of 18 and $20{ }^{\circ} \mathrm{C}$, respectively. In the dynamic climate regime, the temperature was allowed to fluctuate in accordance with outside irradiance within a lower threshold temperature of $15^{\circ} \mathrm{C}$ and an upper temperature of $30^{\circ} \mathrm{C}$, at which point the vents were set to open. The actual temperature setpoint was determined by a light-dependent temperature supplement of $9{ }^{\circ} \mathrm{C}$ per $688 \mathrm{~W} \cdot \mathrm{m}^{-2}$ radiation measured outside the greenhouse. $\mathrm{CO}_{2}$ was not controlled. Artificial lighting (SON-T agro $400 \mathrm{~W}, 96$ $\mathrm{W} \cdot \mathrm{m}^{-2}$ installed effect) was used from 6.00 AM to $11.00 \mathrm{PM}$, starting when outside radiance was below $64 \mathrm{~W} \cdot \mathrm{m}^{-2}$ and stopping at 96 $\mathrm{W} \cdot \mathrm{m}^{-2}$. In the dynamic climate, screens were used during nights and when the outside radiance was below $64 \mathrm{~W}$. In both climate regimes screens were used when irradiance exceeded $500 \mathrm{~W} \cdot \mathrm{m}^{-2}$. An overview of the climatic setup is given in Table 1.

Several climate parameters were measured, the most important ones being temperature and PAR (photosynthetic active radiation, $\mathrm{W} \cdot \mathrm{m}^{-2}$ ). Also vent opening degree was measured. PAR was measured at a weather station (MS900, Senmatic A/S, Denmark, measuring range
0 to $1000 \mathrm{~W} \cdot \mathrm{m}^{-2}$, spectral sensitivity 400 to $1100 \mathrm{~nm}$ ) outside the greenhouse, whereas temperature and vent opening were measured within each greenhouse compartment. The temperature was measured in an aspirated climate box suspended $1 \mathrm{~m}$ above the bench, containing a temperature sensor (RTFC-5, Senmatic $\mathrm{A} / \mathrm{S}$, Denmark, measuring range from -10 to $50{ }^{\circ} \mathrm{C}$, accuracy $\pm 0.3{ }^{\circ} \mathrm{C}$ ). Temperature data were saved every minute, whereas vent opening information was saved every fifth minute.

Statistics. The data were analyzed using SAS Statistical Software (SAS Institute Inc., 1999). The differences in average temperature and vent opening degree between the two climate treatments were analyzed using the SAS ANOVA procedure for weekly analysis of variance on diurnal average temperatures and vent opening degree from each of the eight greenhouse compartments, using climate treatment as class variable. The difference in influx of thrips between the two climate treatments was analyzed using the SAS ANOVA procedure for one-way analysis of variance (covering the 25 -week flying period) of the thrips count on each of the eight sticky traps from each of the eight greenhouse compartments, using climate treatment as class variable.

The correlation between influx of thrips and density of outside thrips and vent open-

Table 1. Important setpoints for the dynamic and traditional climates.

\begin{tabular}{lll}
\hline Setpoint & Dynamic climate & Traditional climate \\
\hline Room temperature day and night & $15^{\circ} \mathrm{C}$ & $18{ }^{\circ} \mathrm{C}$ \\
Light-dependent temperature supplement & $15+9 / 688 \times \mathrm{PAR}^{\mathrm{z}}{ }^{\circ} \mathrm{C}$ & Not used \\
Ventilation at: & $30{ }^{\circ} \mathrm{C}$ & $20^{\circ} \mathrm{C}$ \\
Artificial light, hours & $6.00-23.00$ & $6.00-23.00$ \\
Shade at irradiance at: & $\geq 500 \mathrm{~W} \cdot \mathrm{m}^{-2}$ & $\geq 500 \mathrm{~W} \cdot \mathrm{m}^{-2}$ \\
Screens used at irradiance at: & $<64 \mathrm{~W} \cdot \mathrm{m}^{-2}$ & \\
$\mathrm{CO}_{2}$ & Not controlled & Not controlled \\
\hline
\end{tabular}

${ }^{2}$ PAR (photosynthetic active radiation, $\mathrm{W} \cdot \mathrm{m}^{-2}$ ). ing degree was analysed using the SAS GLM (General Linear Models) procedure for linear regression and covering the 25 -week flying period. The thrips count on each of the eight sticky traps from each of the eight greenhouse compartments and from each of the 25 weeks was related to the average thrips count on the eight outside sticky traps of the corresponding week and to the average vent opening degree of the corresponding greenhouse compartment and week. Average outside thrips count and vent opening degree were used as covariates. The linear regression was repeated, using climate treatment as class variable, allowing parameters for the slope of the regression plane to be calculated separately for the two climate treatments.

\section{Results}

The greenhouse climates resulting from the two climate regimes generally differed throughout the entire experimental period (Fig. 2). When calculated on a weekly basis, the average temperature was higher under the traditional climate during early spring $(18 \mathrm{Feb}$. to 17 Mar. $)(P<0.010)$. During mid-spring (17 Mar. to 7 Apr.), there were no significant differences $(P>0.468)$ between the two cli- 
mates. In late spring, summer and early fall (7 Apr. to 6 Oct.) the average temperature was higher under the dynamic climate regime than under the traditional climate regime $(P<$ 0.028 ) except for weeks 17 and 26. In week 41 there was no significant difference $(P>0.982)$ between the two climates and during late fall (13 Oct. to 1 Dec.) the average temperature was once again higher in the traditional climate $(P<0.047)$.

Additionally, there was a difference in the opening-level of the vents in the two climates. Over the complete 25 -week period, the vents opened on average $7 \%$ under the dynamic regime and $33 \%$ in the traditional climate.
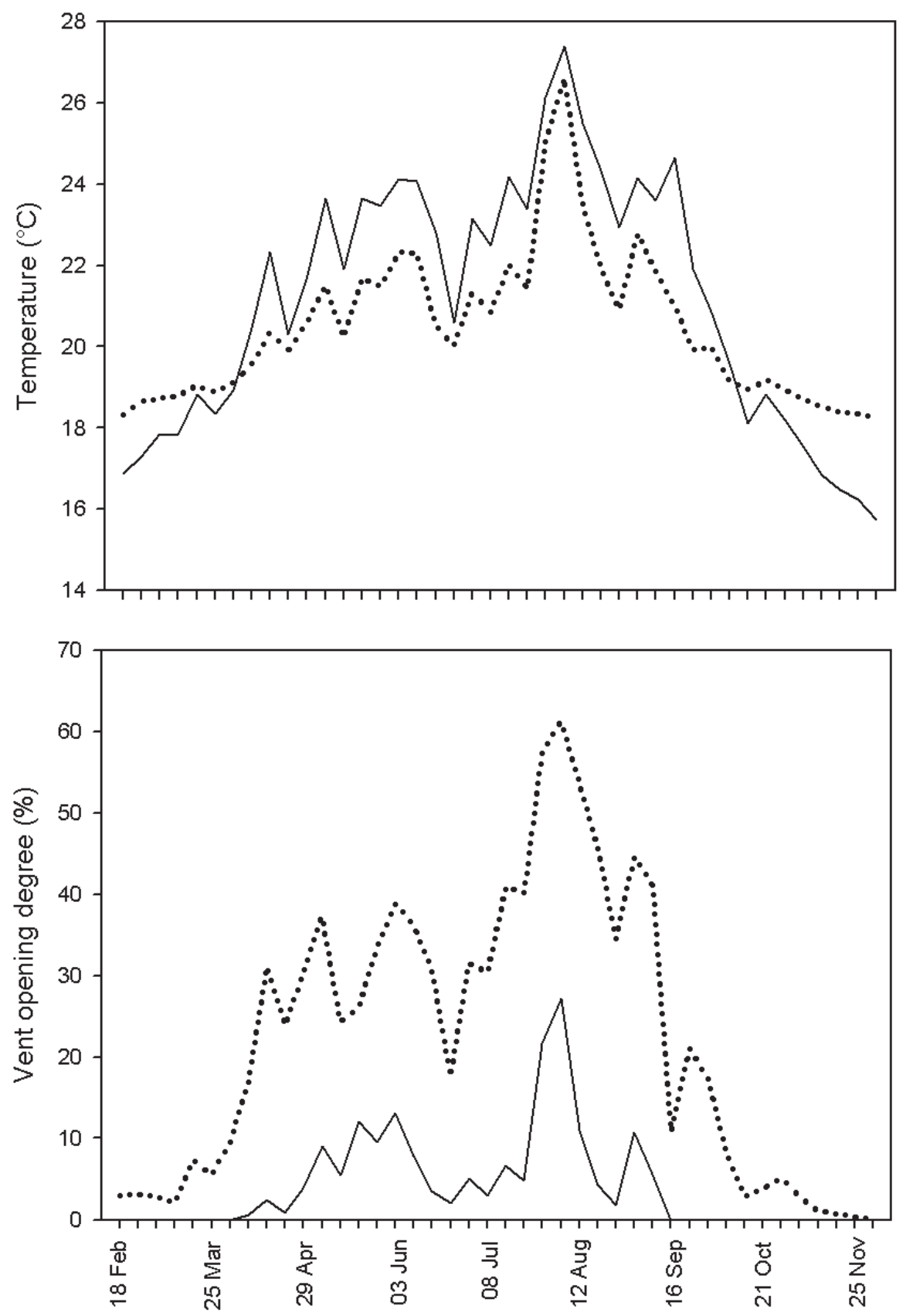

Date

Fig. 2. Weekly average temperature $\left({ }^{\circ} \mathrm{C}\right)$ and weekly average vent opening degree $(\%)$ in a dynamic climate regime and a traditional climate regime between 18 Feb. and 1 Dec. 2004. Full line represent the dynamic climate and dotted line the traditional climate. compartments with a traditional climate (Fig. 3 ). During the observed 25 -week flying period of thrips an average of 2.2 thrips was caught on each trap in the dynamic climate, and 3.9 per trap in the traditional climate regime. The averages cover a span of 0 to 60 thrips per trap in the dynamic climate and 0 to 65 thrips per trap in the traditional climate. There was a significant $(P<0.0001)$ difference in average number of thrips per sticky trap between the two climate regimes when calculated over the 25-week period.

When analyzing data it was found that there was a small but significant difference between yellow and blue sticky traps; more thrips were caught on the yellow traps (SAS GLM, $P=0.047$, $d f=5823$ ). Significant difference was mainly seen in periods when few thrips were caught on traps. However, as the difference was very small and an equal number of yellow and blue sticky traps were used in the experiment no distinction was made in the subsequent analyzes.

Pooled data from both climate regimes showed that influx of thrips was related to density of thrips outside the greenhouse $(P<$ $0.001)$ and the average weekly vent opening degree $(P<0.001)$. The average temperature was not significantly related to the influx $(P<$ $0.0510)$. The relation between number of thrips caught inside and number outside (parameter estimate 0.325 ) was stronger than the relation between numbers of caught thrips inside and vent opening degree (parameter estimate 0.067) (Table 2) (Fig. 4).

When considering the two climate regimes difference could be seen in the relation between influx of thrips and outside density of thrips and vent opening through differences in the parameter estimates (Table 3 ). The relation between the influx and just the outside density was more pronounced for the traditional climate regime (parameter estimate 0.394 ) than for the dynamic regime (parameter estimate 0.271 ).

\section{Discussion}

Results from the present experiment show that the influx of thrips from outside the greenhouse was less where the dynamic climate regime was used. In the observed 25-week flying period of thrips, the influx of thrips into greenhouse compartments with the dynamic climate regime was only a little more than half that of thrips into compartments with a traditional climate regime (average 2.2 thrips in the dynamic climate and 3.9 in the traditional climate regime). The explanation is the difference in vent opening degree of the two climate regimes. The experiment showed a linear dependency of influx on outside density and vent opening degree, the outside density being the most determinant factor for influx. However, outside density was the same for both climate regimes, and thus vent opening degree is the factor responsible for the difference in influx. The fact that influx into compartments with traditional climate regimes seemed to be more dependent on outside density is coupled to the higher average vent opening degree, since this causes a more direct connection between 


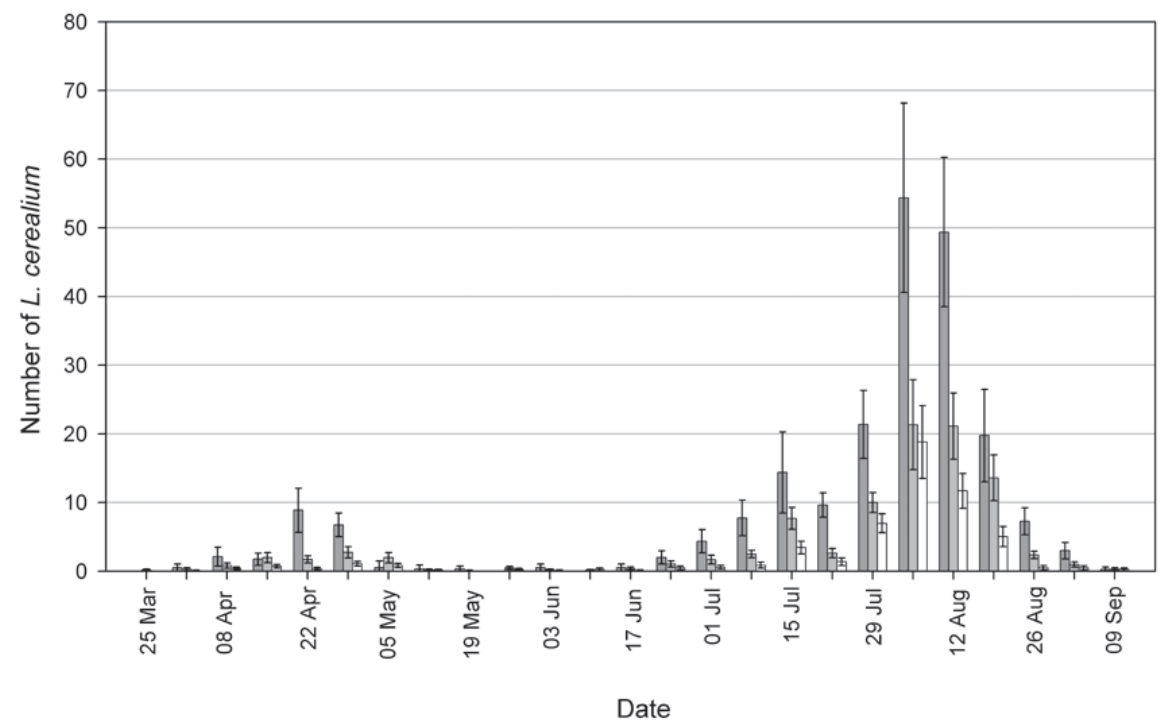

Fig. 3. Average number of thrips per sticky trap in a dynamic climate regime, a traditional climate regime and outside the greenhouse between 25 Mar. and 9 Dec. 2004. Error bars indicate 95\% confidence intervals. White bars represent the dynamic climate, light gray bars the traditional climate and black bars outside.

Table 2. The $R^{2}$ value, parameter estimates and $P$ values of correlations between number of thrips on sticky traps inside the greenhouse compartments and number outside and the average weekly vent opening degree and temperature

\begin{tabular}{lcr}
\hline Parameter & Estimate & $P$ \\
\hline Intercept & -1.109 & $<0.0001$ \\
Thrips on outside traps & 0.325 & $<0.0001$ \\
Vent opening degree (\%) & 0.067 & $<0.0001$ \\
Temperature inside greenhouse & -0.135 & 0.0510 \\
Adjusted $R^{2}$ & 0.54 & \\
\hline
\end{tabular}

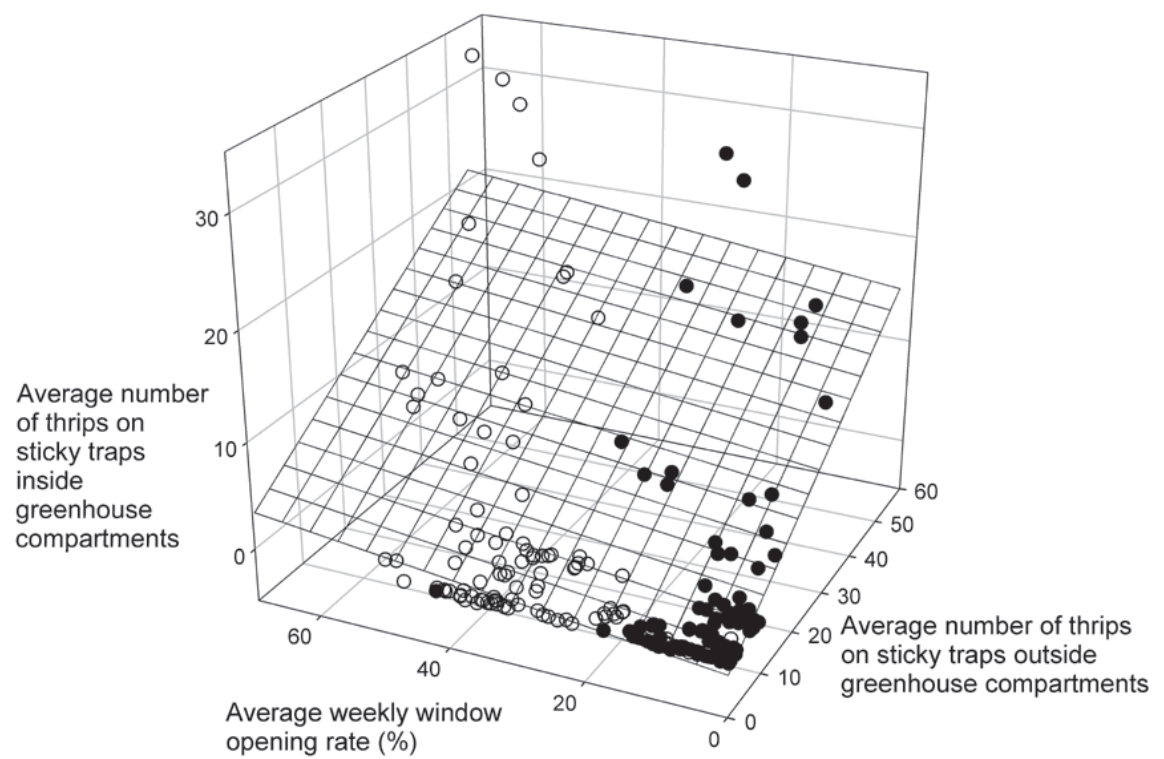

- Dynamic climate

- Traditional climate

Regression plane

Fig. 4. Linear regression correlating influx of thrips with density of thrips outside the greenhouse compartments and average weekly vent opening degree. The figure shows average weekly data for each of the eight compartments, i.e., each point represents the average count on eight sticky traps.

the outside and inside of the greenhouse compartments. The average temperature was close to being significant in relation to the influx. However the statistical $F$ value was very low
$(F=3.8)$ so even if the average temperature had been significant it would have had a very little influence. It might be almost significant as temperature is closely related to the opening degree of the vents (higher temperature with less open vents).

These results thus confirm experiences from commercial greenhouses of fewer pest problems under dynamic climate regimes. The reduction in the influx of pests is influenced by the setpoints for the dynamic climate, which, in the present experiment, was optimal for energy saving, though perhaps not for all greenhouse crops, but at least a broad range of species of potted plants.

In Denmark, according to the Danish Growers' Association, about $40 \%$ of growers are presently testing or using some kind of dynamic climate control (Kronmann, DEG, personal communication). However, the margin between the two temperature thresholds for heating and ventilation is often much narrower than the temperature span in the present experiment. However, it is anticipated that in the near future more growers will apply dynamic climate regimes and operate the system nearer to full capacity, i.e., with a more fluctuating greenhouse climate than today (Kronmann, DEG, personal communication).

Results from the present experiment suggest that a change in the greenhouse climate regime towards a dynamic climate regime could be a method to prevent influx of pests. If combining the choice of climate strategy with a well thought out tactic for operating the vents, climate control manipulation could be a flexible way of preventing influx of pests. In addition to the effect the climate strategy has on the influx of pests, vents can be closed whenever necessary, e.g., during periods when hazardous pests have peaks in their flying activity. Furthermore, when there is no outside pest activity the opportunity for ventilation arises and thereby a possible decrease in the temperature. Development and implementation of warning systems of outdoor insect activity would help decision-making with regard to vent-closing and reduction of pest influx.

Another already existing method to prevent influx of pests is use of insect-proof nets. An advantage of netting is that the exclusion of pests can be close to $100 \%$. However, a disadvantage is that in order to prevent small insects such as thrips from entering, the nets have to be very fine meshed, and this results in increased temperatures due to reduced air circulation (Fatnassi et al., 2002; Molina-Aiz et al., 2004). Fatnassi et al. (2002) found that, in a greenhouse with insect net, it was not possible to lower the temperature enough to compensate for the temperature rise by increasing the opening degree of the vents.

According to the Danish Growers'Association, only $<5 \%$ of growers have installed insect nets in Denmark (Larsen, DEG, personal communication). The high costs of installing insect nets is likely to prohibit them from becoming the main means of insect exclusion under our climatic conditions where insect influx is not continuous all year round. 
Table 3. The $R^{2}$ values, parameter estimates and $P$ values of correlations between the number of thrips on sticky traps inside the greenhouse compartments and the number outside and the average weekly vent opening degree from the traditional and the dynamic climates separately.

\begin{tabular}{|c|c|c|c|c|}
\hline \multirow[b]{2}{*}{ Parameter } & \multicolumn{2}{|c|}{ Dynamic climate } & \multicolumn{2}{|c|}{ Traditional climate } \\
\hline & Estimate & $P$ & Estimate & $P$ \\
\hline Intercept & -0.748 & 0.0002 & -0.748 & 0.0002 \\
\hline Thrips on outside traps & 0.271 & $<0.0001$ & 0.394 & $<0.0001$ \\
\hline Vent opening degree $(\%)$ & 0.088 & 0.0004 & 0.036 & $<0.0001$ \\
\hline Adjusted $R^{2}$ & 0.55 & & 0.55 & \\
\hline
\end{tabular}

\section{Conclusion}

The influx of thrips was influenced by the climate regime, with significantly fewer thrips entering greenhouse compartments controlled by a dynamic climate regime compared to a traditional climate regime. A $40 \%$ reduction of thrips influx was found in the dynamic climate regime. Influx of thrips was correlated to the opening degree of the vents, the vent opening being in average $33 \%$ in the traditional climate and $7 \%$ in the dynamic climate. Prevention of incoming pest by use of climate management could be aflexible method especially along with a kind of outdoor warning systems.

\section{Literature Cited}

Aaslyng, J.M., N. Ehler, P. Karlsen, and E. Rosenqvist, E. 1999. IntelliGrow: A component based climate control system for decreasing the greenhouse energy consumption. Acta Hort. 507:35-41.

Fatnassi,H., T. Boulard, L. Bouirden, and G. Sappe, G. 2002. Ventilation performances of a large Canarian type greenhouse equipped with insect-proof nets. Acta Hort. 559:79-88.

Hanafi, A., R. Bouharroud, S. Miftah, and S. Amouat. 2003. Performances of two types of insect screens as a physical barrier against Bemisia tabaci and their impact on TYLCV incidence in greenhouse tomato in the Souss Valley of Morocco. Bul. OILB/SROP 26(10):39-42.

Hansen, E. 2003. Biologisk bekæmpelse af sommerfuglelarver i væksthusgrøntsager (in Danish). Gartnertidende 36:10-11.

Jakobsen, L., J.M. Aaslyng, and E. Rosenqvist. 2003: Begonia og dynamisk klimastyring. En IntelliGrow rapport (in Danish). Den kongelige veterinær og Landbohøjskole, Institut for Jordbrugsvidenskab, Havebrug. http//www. intelligrow.dk/.

Larsen, A.K. 2000. Insektnet holder mange skadedyr ude (in Danish). Gartnertidende 12:14-15.

Molina-Aiz, F.D., D.L. Valara, andA.J.Alvarez. 2004.

Measurement and simulation of climate inside Almería-type greenhouses using computational fluid dynamics. Agr. For. Meteorol. 125:33-51

Montero, J.I., A. Anton, and P. Munoz. 1999. Performance of an insect-proof screen as covering material in a greenhouse with improved opening surface. Agricoltura mediterranea 129(1):5-12.

SAS Institute Inc. 1999. SAS/STAT software. v. 8.2 SAS for Windows (1999-2001). SAS Inst.Inc., Cary, N.C. 